\title{
Letters
}

\section{Ramifications of screening for breast cancer}

See Research p 689

\section{1 in 4 cancers detected by mammography are pseudocancers}

EDITOR-In this issue Zackrisson et al report on follow-up data from the Malmö mammographic screening trial and conclude that the rate of overdiagnosis of breast cancer was $10 \% .{ }^{1}$ They do not, however, calculate the risk we believe is most relevant to women considering mammography: What is the chance that a screen detected cancer represents overdiagnosis?

After 15 years of follow-up, there were 1320 diagnosed in the screened group and 1205 in the control group (table 1). The excess detection of 115 cancers associated with screening led to their conclusion of an overdiagnosis rate of $10 \%(115 / 1205)$.

However, because the intervention had stopped 15 years earlier and yet breast cancer cases continue to accumulate in both groups, the approach understates the risk of overdiagnosis.

A more relevant denominator is the number of cancers found in the screened group at the end of the trial-741 (table 2). This addresses the question: Were I found to have cancer after being randomised to screening, how likely is it to represent overdiagnosis? As shown in the figure, using this denominator the risk of overdiagnosis is $15 \%(115 / 741)$.

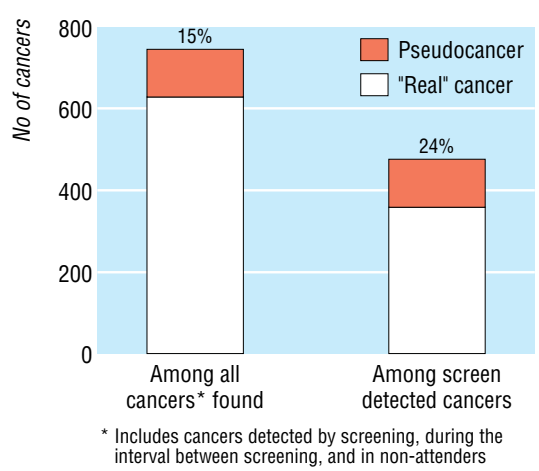

Risk of overdiagnosis in screened group at end of trial

However, many of the cancers detected in the screened group are not detected by screening. They are instead clinically detected (either during the interval between screening examinations or among nonattenders). The most relevant denominator is the number of screen detected cancers found at the end of the trial. This addresses the question: Were I found to have cancer by a mammogram, how likely is it to represent overdiagnosis?

Although this denominator is not reported by Zackrisson et al, the original $B M J$ article describing Malmö reported that $64 \%$ of the cancers detected in the screened group were detected by screening mammography. ${ }^{2}$ Thus one can deduce that the number of screen detected cancers at the end of the trial was about 475 . As shown in the figure, using this denominator the risk of overdiagnosis is $24 \%(115 / 475)$.

H Gilbert Welch professor of medicin h.gilbert.welch@dartmouth.edu Lisa M Schwartz associate professor of medicin Steven Woloshin associate professor of medicine VA Outcomes Group, White River Junction, VT 05009, USA

Competing interests: None declared.

1 Zackrisson S, Andersson I, Janzon L, Manjer J, Garne JP. Rate of over-diagnosis of breast cancer 15 years after end BMJ 2006:332:689-92 scening trial. follow-up study. bmj.38764.572569.7C (published 3 March 2006).

2 Andersson I Andersson I, Aspegren K, Janzon L, Landberg T Lindholm K, Linell F, et al. Mammographic screening and creening trial $B M J 1988$ :297:943-8.

\section{Overdiagnosis in the Malmö trial was} considerably underestimated

EDITOR-Updated results from the Malmö mammography screening trial have suggested that screening caused an overdiagnosis of breast cancer of $10 \%$ in women aged 55-69 years at randomisation. ${ }^{1}$ The authors noted that evidence from randomised trials on the level of overdiagnosis was lacking. This is not correct. On the basis of data from the Malmö trial, ${ }^{2}$ and the two trials from Canada, ${ }^{3}$ we have previously estimated a level of overdiagnosis of $30 \%$ (mean follow-up 8.8 years and 7 years, respectively) $)^{4}$ and have also suggested an overdiagnosis of 33\% in the other Swedish trials, based on number of cancers identified before the control group was screened. ${ }^{5}$

Zackrisson et al followed up the women for an additional 15 years after the trial ended and noted that they could have underestimated the level of overdiagnosis as some asymptomatic women in the control group received mammography. They did not quantify this, but in their original trial report $^{2}$ they noted that $24 \%$ of a random sample of 500 women in the control group had undergone mammography during the trial period at least once. The authors now report ${ }^{1}$ that women aged 55-69 were never invited to screening after the trial ended, but it might be expected that many of themafter having belonged to the control group in a trial for so long-would have undergone mammography at least once subsequently.

If we assume (rather conservatively, compared with the $24 \%$ during the trial) that one quarter of the women had undergone mammography for the first time in their lives during these additional 15 years of follow-up then about half of the women in the control group received mammograms. This would change the estimated level of overdiagnosis from $10 \%$ to about $20 \%$. If we assume that half of these women received mammograms after the trial the estimate becomes $40 \%$. It is therefore essential that the authors provide data on use of mammography after the trial ended.

Because of the unavoidable screening in the control groups of the trials and the small sample size in the Malmö trial and therefore a wide confidence interval for the overdiagnosis estimate, it is necessary to look also at large and long term observational studies of the increase in the incidence of breast cancer after screening was introduced. Such data exist and they show an overdiagnosis of about 40-60\%.5 These estimates could be inflated because of a possible concomitant increase in the use of hormone replacement therapy, which causes breast cancer, but this would only explain a minor part of the increases in the incidence of breast cancer. We therefore believe that our original estimate of $30 \%$ overdiagnosis with screening is still a very reasonable one.

Peter C Gøtzsche director

Nordic Cochrane Centre, Rigshospitalet, DK-2100 Copenhagen $\varnothing$, Denmark pcg@cochrane.dk

Competing interests: None declared.

1 Zackrisson S, Andersson I, Janzon L, Manjer J, Garne JP Rate of over-diagnosis of breast cancer 15 years after end of Malmö mammographic screening trial: follow-up study BMJ 2006;332:689-92. (25 March.) doi:10.1136/ bmj.38764.572569.7C (published 3 March 2006).

2 Andersson I, Aspegren K, Janzon L, Landberg T Lindholm K, Linell F, et al. Mammographic screening and mortality from breast cancer: the Malmo mammographic screening trial. BMJ 1988;297:943-8.

3 Miller AB. The costs and benefits of breast cancer screening. Am J Prev Med 1993;9:175-80

4 Olsen O, Gøtzsche PC. Cochrane review on screening for breast cancer with mammography. Lance 2001;358:1340-2

5 Gøtzsche PC. On the benefits and harms of screening for breast cancer. Int J Epidemiol 2004;33:56-64.

Definition of overdiagnosis is confusing in follow-up of Malmö trial

EDITOR-In their follow-up of the Malmö mammography trial, Zackrisson et al say that the reported levels of overdiagnosis vary 
from $5 \%$ to $50 \% .{ }^{1}$ However, to use cumulative incidence rates at the end of follow-up to quantify the level of overdiagnosis is confusing because the resulting estimates are highly sensitive to both the length of follow-up and the length of screening periods.

Suppose, for example, that during screening from age 40 to 49 the incidence is increased by $50 \%$ and that none of these extra cancers would have been detected in the patient's lifetime in the absence of screening. In this example, the level of overdiagnosis as defined by Etzioni et al would be $50 \%$ irrespectively of when follow-up is performed. ${ }^{2}$ In contrast, the level of overdiagnosis as defined by Zackrisson et al would be $20 \%$ at a follow-up at age 60 but only $7 \%$ at a follow-up at age 80 .

Zackrisson et al reported that the relative incidence rate for women aged 45-69 at randomisation was $1.24(95 \%$ confidence interval 1.12 to 1.39 ) during 10 years of screening. During the 15 year period after screening, a slight reduction in the relative rate $(0.95,0.85$ to 1.06$)$ compensated for only a fraction of the excess cases diagnosed during screening. We reported that during screening the relative rate was 1.45 (1.41 to 1.49) for Swedish women in the last part of the 1990s and that the relative rate fell only slightly later in life. ${ }^{3}$ By analysing data from the screening programme in 11 Swedish counties, Jonsson et al reached a similar conclusion. ${ }^{4}$ We believe that the rising trend in overdiagnosis related to screening since the time of the Malmö trial reflects the development of more sensitive screening methods.

Per-Henrik Zahl senior statistician

Norwegian Institute of Public Health, PO Box 4404 Nydalen, N-0403, Oslo, Norway per-henrik.zahl@fhi.no

Jan Mæhlen professor

Department of Pathology, Ullevål University Hospital, N-0407 Oslo

Competing interests: None declared.

1 Zackrisson S, Andersson I.BMJ, Janzon L, Manjer J, Garne JP. Rate of over-diagnosis of breast cancer 15 years after end of Malmö mammographic screening trial: follow-up study BMJ 2006;332:689-92. (25 March.) doi:10.1136/ bmj.38764.572569.7C (published 3 March 2006).

2 Etzioni R, Urban N, Ramsey S, McIntosh M, Schwartz S, Reid B, et al. The case for early detection. Nat Rev Cancer 2003;3:243-52.

3 Zahl PH, Strand BH, Mæhlen J. Breast cancer incidence in Norway and Sweden during introduction of nation-wide screening: a prospective cohort study $B M J$ 2004;328:921-4.

4 Jonsson H, Johansson R, Lenner P. Increased incidence of invasive breast cancer after the introduction of service screening with mammography in Sweden. Int J Cancer 2005;117;842-7.

\section{Consent for screening}

EDITOR-In 1987, while I was professor of surgery at King's College London, I was given the task of establishing the first mammographic screening unit in southeast England. This followed the findings of the Forrest committee that were announced by Margaret Thatcher two weeks before a general election. My colleagues from the radiology department and I took great pride in setting up a purpose built unit at Camberwell Green, and within a year of receiving our instructions we were up and running and serving as the training unit for the south east of England. I was then appointed to the national steering committee of the NHS breast screening programme.

Working at the "sharp end" provided me with a somewhat different perspective to the epidemiologists, managers, and other servants of the state who served alongside me. I soon learnt first hand of the "toxic side effects" of the process and became increasingly disturbed by the failure of true informed consent among the innocent women who accepted the summons to the screening centre. I am also quite numerate and happened to be running the first national clinical trials unit in my spare time as well. It did not take me long to work out that the $25 \%$ relative risk reduction in breast cancer mortality headlined in the invitations could be framed in another way that described the absolute benefits (number needed to screen over 10 years to save one death from breast cancer 1000).

I soon became a thorn in the side of the programme's committee, and things came to a head in 1997 when I found myself in a minority of one in demanding that the information leaflets expressed benefits in absolute numbers and described harms in an open and fair way. The concern of the committee at that time was that such information would deter women from attending and the target of $>70 \%$ acceptance, on which the programme was predicated, would be missed. This perfectly illustrates the conflict of interest that Jørgensen and Gøtzsche describe. ${ }^{2}$ At this point I did the honourable thing and resigned from the committee. As a surgeon I have a legal and ethical commitment to describe to my patients the harms and the benefits of my interventions, but a double standard clearly exists among the screening community, who seem to be in denial. Well, at least they can't deny the problem of overdiagnosis that was finally confirmed by irrefutable evidence in the online $B M J$ publication of the Malmö trial follow-up.

Michael Baum professor emeritus of surgery, University College London

Portland Hospital, London W1N 6AH

Portland Hospital, London W1N
michael@mbaum.freeserve.co.uk

Competing interests: None declared.

1 Baum M. Screening for breast cancer, time to think-and stop? Lancet 1995;346:436-7.

2 Jørgensen KJ, Gøtzsche PC, Content of invitations for publicly funded screening mammography. $B M J$ 2006;332:538-41. (4 March.)

3 Zackrisson S, Andersson I, Janzon L, Manjer J, Garne JP. Rate of over-diagnosis of breast cancer 15 years after end of Malmö mammographic screening trial: follow-up study. BMJ 2006:332:689-92. (25 March.) doi:10.1136 bmj.38764.572569.7C (published 3 March 2006).

\section{More debate and better information still} needed

EDIToR-Rather than end the debate about screening, as Dixon's editorial suggests, ${ }^{1}$ and look to the future, it would be preferable to raise the current level of debate by presenting balanced arguments, avoid misleading presentation of statistics, and consider current evidence about over-treatment ${ }^{2}$ and poor quality information. ${ }^{3}$ Efforts may have been made, as Dixon says, to provide women with sufficient information to make an informed choice, but they have not been successful: the quality still falls far short. The criticism made in 2003 is still valid. ${ }^{4}$

Barratt et al have since devised a model of outcomes of mammographic screening showing estimates of benefits and harms that is readily usable by women considering breast screening. ${ }^{5}$ They advise that comprehensive information about cancer screening, in line with recommendations from the General Medical Council, should be bal-

anced (describing benefits anced (describing benefits frame, such as 10 years) and that estimates should be presented with a constant denominator (such as per 100 or per 1000 people). This $\times$ model and advice, and other decision aids and tools are available, but none has been provided by the NHS breast screening programme to women, as recommended in $2003 .^{4}$

If breast screening is to move on, then it is time the proponents of breast screening moved on, not just to the future, but to the present. Women today do not want to be patronised, or fobbed off with unbalanced, insufficient information, but to be treated with respect, so that they can make up their own minds. Decision making, to give proper consent, requires good quality information. It is evident that they are not getting it. ${ }^{3}$

Hazel Thornton honorary visiting fellow, Department of Health Sciences, University of Leicester

"Saionara," Rowhedge, Colchester CO5 7EA hazelcagct@keme.co.uk

Competing interests: None declared.

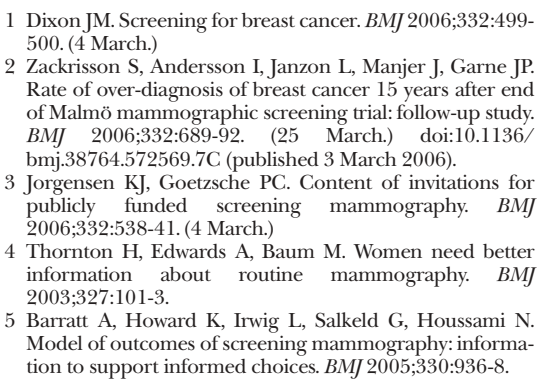

1 Dixon JM. Screening for breast cancer. BMJ 2006;332:499500. (4 March.)

2 Zackrisson S, Andersson I, Janzon L, Manjer J, Garne JP. Rate of over-diagnosis of breast cancer 15 years after end of Malmö mammographic screening trial: follow-up study. BMJ 2006;332:689-92. (25 March.) doi:10.1136 bmj.38764.572569.7C (published 3 March 2006).

3 Jorgensen KJ, Goetzsche PC. Content of invitations for publicly funded screening mammography. $B M J$ 2006;332:538-41. (4 March.)

4 Thornton H, Edwards A, Baum M. Women need better information about routine mammography. $B M J$ 2003;327:101-3.

5 Barratt A, Howard K, Irwig L, Salkeld G, Houssami N Model of outcomes of screening mammography: information to support informed choices. BMJ 2005;330:936-8.

\section{Prophylactic heparin in palliative care}

\section{A cautious welcome...}

EDITOR-Although we agree with the conclusions of the survey reported by Noble et al of patients' views on receiving low molecular weight heparin in palliative care, we wish to sound some notes of caution. Reasons other than preciousness about 
patients' comfort lie behind a reluctance to give many patients in palliative care prophylactic treatment with low molecular weight heparin.

In advanced cancer the procoagulant state is not temporary, as after surgery. Progression of disease is also associated with worsening mobility, sometimes venous obstruction by tumour masses, and sometimes poor hydration. Therefore if it is logical to put patients on heparin while in an institutional setting, it would be illogical to stop this when they go home. This means problems associated with long term heparin administration beyond the economic and manpower issues (see full version on bmj.com). The benefits and risks of low molecular weight heparin in the end stages of cancer still have to be quantified. The prevalence of breathlessness from recurrent small emboli or a postphlebitic syndrome in palliative care is as yet undetermined, although many of us believe the former is actually quite common.

If the same study had been carried out in a hospice, where patients may be less in "aggressive treatment" mode and staff less oriented to active treatment, would patients' enthusiasm for prophylaxis have been correspondingly dampened? (If so, this invites all kinds of questions about patients' choice in either setting). Patients were also given heparin before they were presented with the questionnaire. We assume that they consented to the treatment; does this mean it was a self selected group, which might bias the results?

The current gaps in our knowledge should not preclude us from using prophylactic heparin more widely, but other factors have to be weighed up in addition to patients' comfort in judging when to use it.

Victor Pace consultant in palliative medicine v.pace@stchristophers.org.uk

Emma Hall consultant in palliative medicine

Catherine Bailey specialist registrar

St Christopher's Hospice, London SE26 6DZ

Competing interests: None declared.

Noble SIR, Nelson A, Turner C, Finlay IG. Acceptability of low molecular weight heparin thromboprophylaxis for inpatients receiving palliative care: qualitative study. $B M J$ 2006;332:577-80. (11 March.)

\section{...to a challenging idea}

EDITOR-Twenty eight (100\%) hospice inpatients at least five days into thromboprophylaxis with low molecular weight heparin found it acceptable. ${ }^{1}$ The potential for lengthened life appeared the main reason for wanting prophylaxis and none knew any common symptoms of venous thromboembolism. All had irreversible deteriorations in performance status, and, as cancer itself is a risk for venous thromboembolism, any case for low molecular weight heparins for hospice inpatients logically continues for life.
Such thromboprophylaxis in advanced cancer does not improve one year survival. It possibly reduces the risk of symptomatic venous thromboembolism by $20 \%$ but bleeding complications rise by $80 \%$. Administering low molecular weight heparin to 190 patients with advanced cancer might prevent one symptomatic venous thromboembolism. Based on these figures, our charity's annual drug costs would increase by roughly $28 \%$ ( $£ 6970 ; € 10051 ; \$ 12245$ ) to provide low molecular weight heparin to all our inpatients, and the associated health cost of preventing less than one symptomatic venous thromboembolism per year would include 3.5 extra bleeding complications, without demonstrably lengthening a single life.

The non-maleficence of avoiding daily injections might not wholly explain the infrequency of thromboprophylaxis with low molecular weight heparin in hospices. Palliation is the alleviation of symptoms without necessarily eradicating their causes. Palliative care affirms life but regards dying as a normal process and intends neither to hasten nor to postpone death. ${ }^{3}$ In contrast, prophylaxis is the pre-
emptive attempt to prevent symptoms that may never arise anyway. Prophylactic treatments are often continued in hospices until their risks outweigh their benefits, but using hospice admission to trigger initiation of pharmacological prophylaxis that is perhaps mistakenly understood by patients to lengthen life rather than prevent symptoms is a conceptually and culturally challenging step for many.

John C Chambers Macmillan consultant Katharine House Hospice, Adderbury, Oxfordshire OX17 3NL

dr.ch@mbers.info

Competing interests: None declared.

1 Noble SIR, Nelson A, Turner C, Finlay IG. Acceptability of low molecular weight heparin thromboprophylaxis for inpatients receiving palliative care: qualitative study. $B M$ 2006;332:577-80. (11 March.)

2 Kakkar AK, Levine MN, Kadziola Z, Lemoine NR, et al Low molecular weight heparin, therapy with dalteparin, and survival in advanced cancer: the fragmin advanced malignancy outcome study (FAMOUS). J Clin Oncol 2004;22:1944-8.

3 World Health Organization. Definition of palliative care. www.who.int/cancer/palliative/definition/en/ (accessed 13 Mar 2006)

\section{Effectiveness of hip protectors}

\section{Wider picture is important}

EDITOR-I am sure that many of us at the "sharp end" of hip fracture management will not be surprised at the findings expressed by Parker et al that hip protectors may not be effective in preventing hip fractures. ${ }^{1}$ In many cases, a careful history (where the patient's circumstances permit) will show that the fracture preceded the fall and was its cause, not its result. Ideal confirmation of this comes when the sound of the fracture has been heard by a bystander or carer, but in the nature of things this occurs in only a small number of cases: it may none the less represent the commonest sequence of events and point to the underlying pathological process.

Prevention of hip fractures must be directed to a much earlier stage of life, before the "at risk" age group is reached. Successful prophylactic measures may be effective for the next generations, although it's probably too late for the current population at risk.

Kenneth Nesbitt accident and emergency specialist (retired)

Magherafelt BT45 5 HB

k.nesbitt@doctors.net.uk

Competing interests: None declared.

I Parker MJ, Gillespie WJ, Gillespie LD. Effectiveness of hip protectors for preventing hip fractures in elderly people: systematic review. BMJ 2006;332:571-4. (11 March.)

\section{It's more the effectiveness of compliance} strategies

EDITOR-I write with reference to the systematic review by Parker et al. ${ }^{1}$ Adherence is certainly an issue, and needs to be addressed organisationally as well as at the level of the individual. However, given that many of those people seen as possible beneficiaries are cognitively or physically impaired and living in institutions, I think the question of consent is also an issue. I guess most $B M J$ readers would prefer not to wear special pants for the last 20 or so years of their lives, even if avoiding a hip fracture could be guaranteed. Avoiding a fall is better than wearing a hip protector (most falls don't result in a hip fracture, but they are all very unpleasant for the faller) so hip protectors should not be seen as a substitute for a falls prevention programme.

McCrea in his rapid response to Parker et al suggests that hip fracture is caused by the joint and musculature being brought to the end of its range of movement, but the evidence points to the impact of a fall as the usual cause..$^{2-5}$

Peter D O'Halloran lecturer

Nursing and Midwifery Research Unit, Queen's University, Belfast BT9 5AF

p.ohalloran@qub.ac.uk

Competing interests: None declared.

1 Parker MJ, Gillespie WJ, Gillespie LD. Effectiveness of hip protectors for preventing hip fractures in elderly people: systematic review. BMJ 2006;332:571-4. (11 March.)

2 Hayes WC, Myers ER, Morris JN, Gerhart TN, Yett HS, Lipsitz LA. Impact near the hip dominates fracture risk in elderly nursing home residents who fall. Calcif Tissue Int 1993;52:192-8.

3 Hopkinson-Woolley JA, Parker MJ. Fractures of the hip: does the type of fall really affect the site of fracture? Injur 1998;29:585-7.

4 Schwartz AV, Kelsey JL, Sidney S, Grisso JA. Characteristics of falls and risk of hip fracture in elderly men. Osteoporosis Int 1998;8:240-6.

, Greenspan SL, Myers ER, Kiel DP, Parker RA, Hayes WC Resnick NM. Fall direction, bone mineral density, an function: risk factors for hip fracture in frail nursing hom elderly. Am J Med 1998;104:539-45. 


\section{Ethics committees}

\section{Current research ethics forms are an} over-reaction that will stifle research

EDITOR-I was grateful to read Masterton's experiences of local research ethics committees. ${ }^{1}$ The current state of affairs has been brought about in response to the Data Protection Act and by a probable overreaction to the Alder Hey affair. However, such is the bureaucratic minefield that any researcher must now traverse to seek ethical approval, even for small scale local research projects, that exploratory clinical and health services research will be stifled. In particular, junior researchers and those not working with teams well versed in processing appli-

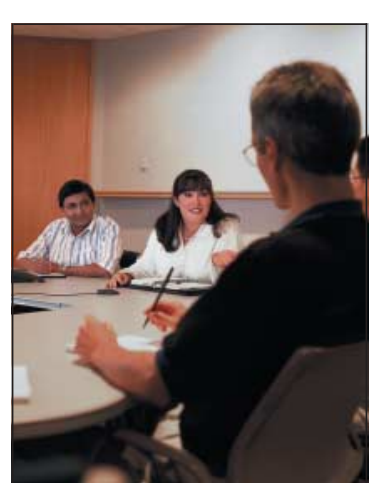

asked to take part in two research projects, both of which were unethical. On each occasion I was actually present when staff tried to conduct studies on close relatives who were either vulnerable at the time or could not give consent. We need ethics committees, and they need input not only from doctors and researchers but also from lay people and others with different expertise.

Oliver's complaints about the form (previous letter) should be taken more seriously, although I have yet to receive a form that comes anywhere near the 150 pages of his submission. The longest application form at my last research ethics committee meeting was 28 pages for a major drug trial. Even so everyone, especially the Central Office for Research Ethics Committees (COREC), is working to improve and simcations, will find many projects strangled at birth by red tape.

In reality, the key questions to be addressed by any research ethics committee can be distilled to:

- Are the researchers tackling a worthwhile question?

- Is there sufficient "equipoise" to justify exploring it (has the answer already been provided repeatedly)?

- Are they using sound research methods to address the question? (performing work of a design of quality which cannot hope to answer the question posed would not be ethical)-although this is arguably a matter for expert peer review rather than an ethics committee.

- Is there any chance of harms to research participants? If so, how can these be minimised and is the risk justifiable?

- How will valid and fully informed consent

be obtained? Is it ethical not to seek it?

- What will happen to data? (Anonymisation, storage, etc.)

In reality, these key questions could be answered on one side of A4, yet the current form runs into over 150 (often very repetitive) pages, as a personal example shows (see full version on bmj.com).

David Oliver senior lecturer, elderly care medicine University of Reading, Institute of Health Sciences, Reading RG6 1HY

D.Oliver@reading.ac.uk

Competing interests: None declared.

1 Masterton G. Two decades on an ethics committee. BMJ 2006;332:615. (11 March.)

\section{We all need research ethics committees}

EDITOR-Nothing seems to get under the skin of a minority of the medical profession more than the existence of research ethics committees, as is shown by the responses to Masterton's recent personal view. ${ }^{12}$

I have been a member of our local committee for nearly 10 years and its chairman for three. Earlier on in my medical career, close members of my family were

plify the form and reduce not only the detail required but also the inevitable overlap with forms for research governance. Oliver's key questions are important, but there are others that need answering too for some projects-more than two sides of A4.

Ethical assessment of research is not going to go away; it is not going to go back to being a little local committee of easygoing colleagues. It behoves us, researchers and ethics committees both, to work together to establish a workable system that supports and encourages research at the same time as protecting patients. The system should integrate with research governance and be timely.

G Michael Addison retired chemical pathologist Cheshire SK9 5DE

mike.addison@man.ac.uk

Competing interests: GMA is chair, Salford and Trafford Local Research Ethics Committee. 1 Masterton G. Two decades on an ethics committee. $B M$ J
2006;332:615. (11 March.)
2 Electronic responses to Masterton G. Two decades on an
ethics committee. bmj.com 2006. http://
bmj.bmjjournals.com/cgi/eletters/332/7541/615

\section{Approval of inhaled insulin in Europe and United States}

EDITOR-We wish to respond to several points in the news item by Lenzer on the approval of inhaled insulin. ${ }^{1}$

Firstly, the article states that critics say that Exubera fails to control postprandial glucose presentations as well as subcutaneous insulin. In fact, in clinical trials Exubera is comparable or superior to subcutaneous human insulin in terms of postprandial glucose control..$^{2-4}$

Secondly, the article raises concerns about the pulmonary effects of Exubera. Pfizer has already collected and is committed to the ongoing collection of extensive safety data on pulmonary function. Having examined the data, both the EMEA and FDA have approved Exubera for use in adults. Although small, clinically insignificant, reductions in $\mathrm{FEV}_{1}$ were noted in clinical trials, the changes occurred early, the rate of change compared with comparator groups did not change after the first three to six months, and resolution was seen in patients with both type 1 and type 2 diabetes soon after stopping Exubera.

It is also important to distinguish the inhalation of irritant "dusts" from the inhalation of insulin, which has undergone extensive safety testing. Exubera has been studied in over 3500 patients in clinical trials, some for as long as seven years, and there is no evidence to date that Exubera causes any "lung diseases."

The article also states that critics raised concerns about pulmonary effects and erratic absorption even in patients who were exposed to secondary tobacco smoke. To clarify, there is no evidence of "erratic absorption" in non-smokers. However, Exubera is contraindicated in smokers or people who have smoked in the preceding six months, in accordance with recommendations from diabetes associations, since smoke interferes with the absorption of Exubera.

With regard to the comments made about dosing in milligrams and not units, the education of healthcare professionals on this aspect of prescribing Exubera will be extensively covered in Pfizer's training programme. Clear guidance will be given in the form of training and reference materials, and a website (www.INHprogramme.co.uk) will soon be live which will facilitate and enhance this training.

Finally, the article states that Exubera is to be marketed jointly by Pfizer and SanofiAventis. On 12 January Pfizer announced that is had reached an agreement to acquire the Sanofi-Aventis worldwide rights to Exubera.

Bruce Charlesworth head of RMRS and medical affairs

Pfizer Limited, Walton Oaks, Walton-on-the-Hill, Tadworth, Surrey KT20 7NS

bruce.charlesworth@pfizer.com

Competing interests: BC works for Pfizer.

1 Lenzer J. Inhaled insulin is approved in Europe and United States. BMJ 2006;332:321. (11 February.)

2 Quattrin T, Belanger A, Bohannon NJ, Schwartz SL, the Exubera Phase III Study Group. Group: Efficacy and safety of inhaled insulin (Exubera) compared with subcutaneous insulin therapy in patients with type 1 diabetes: results of a 6-month, randomized comparative trial. Diabetes Care 2004;27:2622-7.

3 Skyler JS, Weinstock RS, Raskin P, Yale JF, Barrett E, Gerich $\mathrm{JE}$, et al. Use of inhaled insulin in a basal/bolus insulin regimen in type 1 diabetic subjects. Diabetes Care 2005;28:1630-5.

4 Hollander PA, Blonde L, Rowe R, Mehta AE, Milburn JL Hershonet KS, al. Efficacy and safety of inhaled insulin (Exubera) compared with subcutaneous insulin therapy i patients with type 2 diabetes. Diabetes Care 2004;27:235662.

\section{bimj.com}

We select the letters for these pages from the rapid responses posted on bmj.com within five days of publication of the article to which they refer.

Letters are thus an early selection of rapid responses on a particular topic. Readers should consult the website for the full list of responses and any authors replies, which usually arrive after our selection. 